\title{
Tough Nanocomposite lonogel-based Actuator Exhibits Robust Performance
}

SUBJECT AREAS:

ACTUATORS

GELS AND HYDROGELS

Received

9 July 2014

Accepted

3 September 2014

Published

20 October 2014

Correspondence and requests for materials should be addressed to

B.H. (hebin@tongii. edu.cn) or Q.W.

(wangqg66@tongii. edu.cn)

* These authors contributed equally to this work.
Xinhua Liu'*, Bin He $2 *$, Zhipeng Wang ${ }^{2}$, Haifeng Tang², Teng Su' \& Qigang Wang'

\author{
'Department of Chemistry and Advanced Research Institute, Tongii University, Shanghai 200092 (P. R. China), ${ }^{2}$ Department of \\ Control Science and Engineering, Tongii University, Shanghai 201804 (P. R. China).
}

Ionogel electrolytes can be fabricated for electrochemical actuators with many desirable advantages, including direct low-voltage control in air, high electrochemical and thermal stability, and complete silence during actuation. However, the demands for active actuators with above features and load-driving ability remain a challenge; much work is necessary to enhance the mechanical strength of electrolyte materials. Herein, we describe a cross-linked supramolecular approach to prepare tough nanocomposite gel electrolytes from HEMA, $\mathrm{BMIMBF}_{4}$, and $\mathrm{TiO}_{2}$ via self-initiated UV polymerization. The tough and stable ionogels are emerging to fabricate electric double-layer capacitor-like soft actuators, which can be driven by electrically induced ion migration. The ionogel-based actuator shows a displacement response of $5.6 \mathrm{~mm}$ to the driving voltage of $3.5 \mathrm{~V}$. After adding the additional mass weight of the same as the actuator, it still shows a large displacement response of $3.9 \mathrm{~mm}$. Furthermore, the actuator can not only work in harsh temperature environments $\left(100^{\circ} \mathrm{C}\right.$ and $\left.-10^{\circ} \mathrm{C}\right)$ but also realize the goal of grabbing an object by adjusting the applied voltage.

E lectrochemical actuators have been intensively developed over the past decades due to their desired mechanical performance in intelligent robots, which are convenient substitutes for air- and fluid-derived devices $^{1-5}$. Their typical structure is composed of one ionically conductive electrolyte sandwiched by two electrically conductive electrodes, which can bend to allow the redistribution of different sizes of cations and anions under applied voltage ${ }^{6-8}$. Relative to the well-developed electrode materials, the electrolytes originated from electro-active polymers (EAP) are rarely discussed ${ }^{9-15}$. For the electronic EAPs (such as electrostrictive and dielectric polymers), the high electrical fields required for effective displacement has limited their broad application due to safety reasons ${ }^{2,16-19}$. Ionic EAPs including ionic polymer metal composites (IPMC) and gels are suitable electrolytes to fabricate actuators, which can be driven under voltage as low as $1-5 \mathrm{~V}^{7,20-23}$. A typical actuator with water-swollen nafion films and metal electrodes can produce large bending displacements and high force densities ${ }^{24,25}$. However, there is a need to maintain their moisture and chemical stability. To address this issue, the ionogels with flexible ionic conductivity are more appropriate building blocks for the evolution of actuators due to easy ion transport, chemical and thermal stability $26-29$.

As pioneering examples, gel electrolytes of polymer/ionic liquids have been used to fabricate electrochemical actuators, which can quickly move in air with low voltage ${ }^{10}$. Chen's group has reported a series of actuators fabricated by electrolyte membranes of bio-polymer chitosan or fluorinated polymer/ionic liquids ${ }^{30-32}$. The good compatibility of ionic liquid with polymer allows the effective ion transportation within electrolyte, exhibiting considerable bending actuation behaviour at low applied voltage. Another typical work done by Aida's group is the bucky gel-based actuator with polymer-supported ionic-liquid layer ${ }^{33-36}$. The polymer electrolyte for the ideal fabrication of actuator should be mechanically strong to achieve effective loading ability ${ }^{37,38}$. The current ionic polymer gels prepared by simple blending or by covalent polymerization of vinyl monomers do not have sufficient mechanical strength for this requirement. Recently, ionogels formed by the supramolecular effect between block copolymers and ionic liquids with/without nanofiller have exhibited high mechanical strength ${ }^{39-43}$. The non-covalent interactions can endow the gels with high mechanical strength and superior self-healing ability to supramolecular materials $\mathrm{s}^{44-50}$. Inspired by these pioneering studies, we employed $\mathrm{TiO}_{2}$ nanoparticles to initiate photo-polymerization to prepare a supramolecular nanocomposite ionogel that possesses both the mechanical strength of polymer and the electrochemical behaviour of ionic liquid.

\section{Results}

Preparation of ionogel. Our ionogel electrolytes can be simply prepared from the following components: 1butyl-3-methylimidazolium tetrafluoroborate $\left(\mathrm{BMIMBF}_{4}\right)$, hydroxyethyl methacrylate (HEMA), and $\mathrm{TiO}_{2}$ 


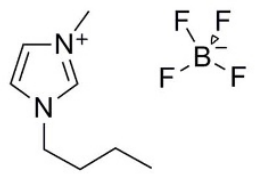<smiles>C=C(C)C(=O)OCCO</smiles>
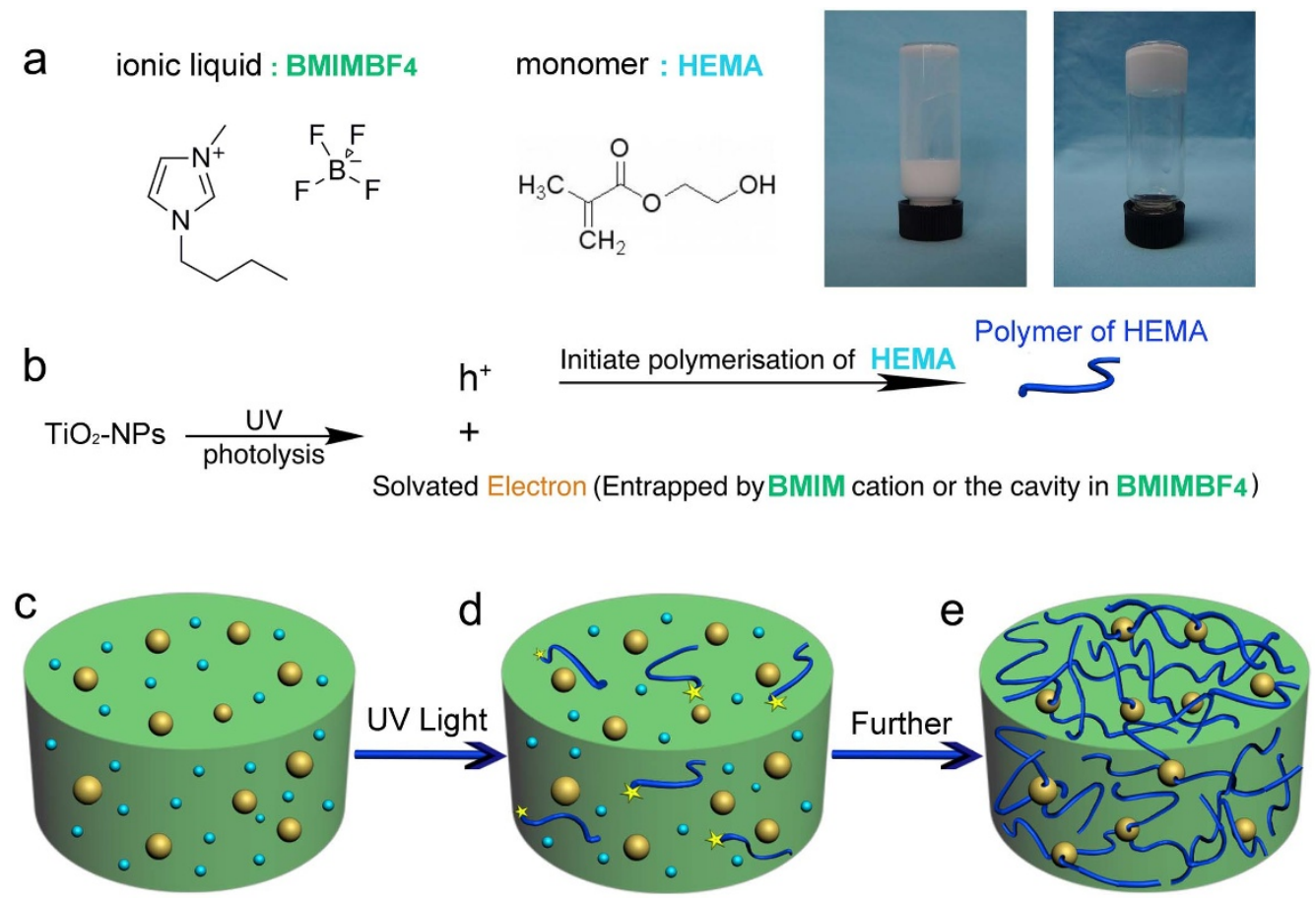

- $\mathrm{TiO}_{2}-\mathrm{NPS}$

- monomer

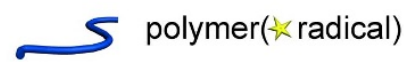

ionic liquid

Figure $1 \mid$ Proposed mechanism of the $\mathrm{BMIMBF}_{4}$-based ionogel under UV light. (a) Molecular structures of $\mathrm{BMIMBF}_{4}$ and $\mathrm{HEMA}$. (b) The TiO $2^{-}$

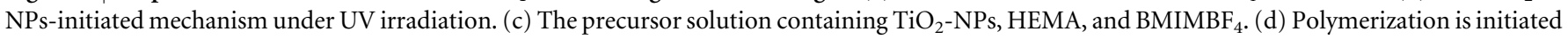
by the $\mathrm{TiO}_{2}$-NPs. (e) The $\mathrm{TiO}_{2}$-NPs and PHEMA are cross-linked to develop a 3D network.

nanoparticles ( $\mathrm{TiO}_{2}-\mathrm{NPs}$ ) (Figure 1a). Firstly, $0.01 \mathrm{~g} \mathrm{TiO}_{2}-\mathrm{NPs}$ and $0.10 \mathrm{~g}$ HEMA are dissolved in $0.89 \mathrm{~g} \mathrm{BMIMBF}_{4}$ via magnetic stirring to form a viscous solution (Figure 1c). Then, BMIMBF$_{4}$-based ioniogels can be formed by irradiating the as-prepared homogeneous solution with UV light (Figures $1 \mathrm{~d}$ and $1 \mathrm{e}$ ). $\mathrm{TiO}_{2}-\mathrm{NPs}$ have demonstrated the ability to trigger photo-initiated polymerization during heterogeneous polymer synthesis. The UV-generated hole $\left(\mathrm{h}^{+}\right.$) from $\mathrm{TiO}_{2}$-NPs (Figure $1 \mathrm{~b}$ ) is the initiator for the polymerization of HEMA; it can directly react with non-covalently adsorbed HEMA to form a surface monomer radical by abstracting hydrogen. The existence of long-lived propagating radicals has been confirmed by the electron paramagnetic resonance (EPR) spectrum of the $\mathrm{BMIMBF}_{4}$ solution containing $\mathrm{TiO}_{2}-\mathrm{NPs}$ and HEMA during UV irradiation. The $\mathrm{TiO}_{2}$-NPs should be taken as the non-covalent cross-linking points for the formation of nanocomposite ionogel. Our $\mathrm{BMIMBF}_{4}$ based ioniogel is free of any additional cross-linker and conventional initiator, which may hamper the electrochemical performances.

Characteristics and mechanical properties of ionogels. To understand the gelation kinetics of such a system, we conducted time sweep measurements to monitor the storage modulus $\left(\mathrm{G}^{\prime}\right)$ and loss modulus $\left(G^{\prime \prime}\right)$ as a function of time (Figure $2 \mathrm{a}$ ). A crossover point between $G^{\prime}$ and $G^{\prime \prime}$ curves appears at 15 minutes, indicating the rapid gelation process of this system. At the equilibrium point after 55 minutes, the value of $G^{\prime}$ is 3.5 times larger than that of $G^{\prime \prime}$, indicating the formation of an elastic gel. Additionally, the final conversion of the monomer is over $96 \%$ after 60 minutes of UV irradiation (Figure S1), which is supported by the measurement of thermo-gravimetric trace (TGA). The mass loss of volatiles resulting from the residue monomers can be detected by TGA due to the thermal stability of ionic liquid and the formed polymer ${ }^{51}$.

The $\mathrm{BMIMBF}_{4}$ based ionogel shows a high level of toughness when undergoing large deformations and does not show any sign of damage under compression. The compression tests reveal that the increase in $\mathrm{TiO}_{2}-\mathrm{NPs}$ enhances the compressive properties of the gel (Figure 2b). Because the modulus at the beginning stage and the compressive strength at a strain of $98 \%$ follow similar trend, the Young's modulus in the compression test was selected as the mechanical index for the optimisation of synthetic conditions. The value of Young's modulus increases from $4.10 \mathrm{kPa}$ to $7.87 \mathrm{kPa}$ as the amount of $\mathrm{TiO}_{2}$-NPs increases from $0.2 \mathrm{wt} \%$ to 1 wt $\%$ (Table S1). The increase in $\mathrm{TiO}_{2}$-NPs should lead to more cross-linking sites and higher conversion, which both contribute to the final mechanical performance. When the amount of $\mathrm{TiO}_{2}-\mathrm{NPs}$ increases from 1 wt $\%$ to $1.5 \mathrm{wt} \%$, the value of Young's modulus only increases from $7.87 \mathrm{kPa}$ to $9.13 \mathrm{kPa}$. Further increase in $\mathrm{TiO}_{2}-\mathrm{NPs}$ would cause transmittance problem due to the photo-scattering with large quantities of $\mathrm{TiO}_{2}-\mathrm{NPs}$. The optimised amount of $\mathrm{TiO}_{2}-\mathrm{NPs}$ was selected to be $1 \mathrm{wt} \%$ after comprehensive consideration of the aforementioned data and the relatively large tensile deformation and tensile strength (Figure S2).

A morphological analysis of the cryo-dried sample using scanning electron microscopy (SEM) indicates that the porous microstructures occur ubiquitously in the ioniogels (Figure $2 \mathrm{~d}$ ). $B M \mathrm{BMBF}_{4}$ is a type of ionic liquid with special properties including low melting point, high conductivity and negligible vapour pressure. The gelated $\mathrm{BMIMBF}_{4}$ can still maintain a relatively high ionic conductivity of $1.4 \mathrm{mS} \mathrm{cm}^{-1}$ (Figure S3) because of the porous 3D-network in the ionogel. It has been demonstrated previously that the conductive ionogel with interpenetrating polymer network architecture can be used as an appropriate solid-state-electrolyte for soft actuator ${ }^{52}$.

Driving behaviors of actuators. The configuration of the ionogelbased actuator is shown in Figure 3a. The architecture of the described flexible actuator is comparable to the electric-doublelayer supercapacitor. The middle layer is the ionogel that contains a high content of ionic liquid as the electrolyte. The outer layers of 

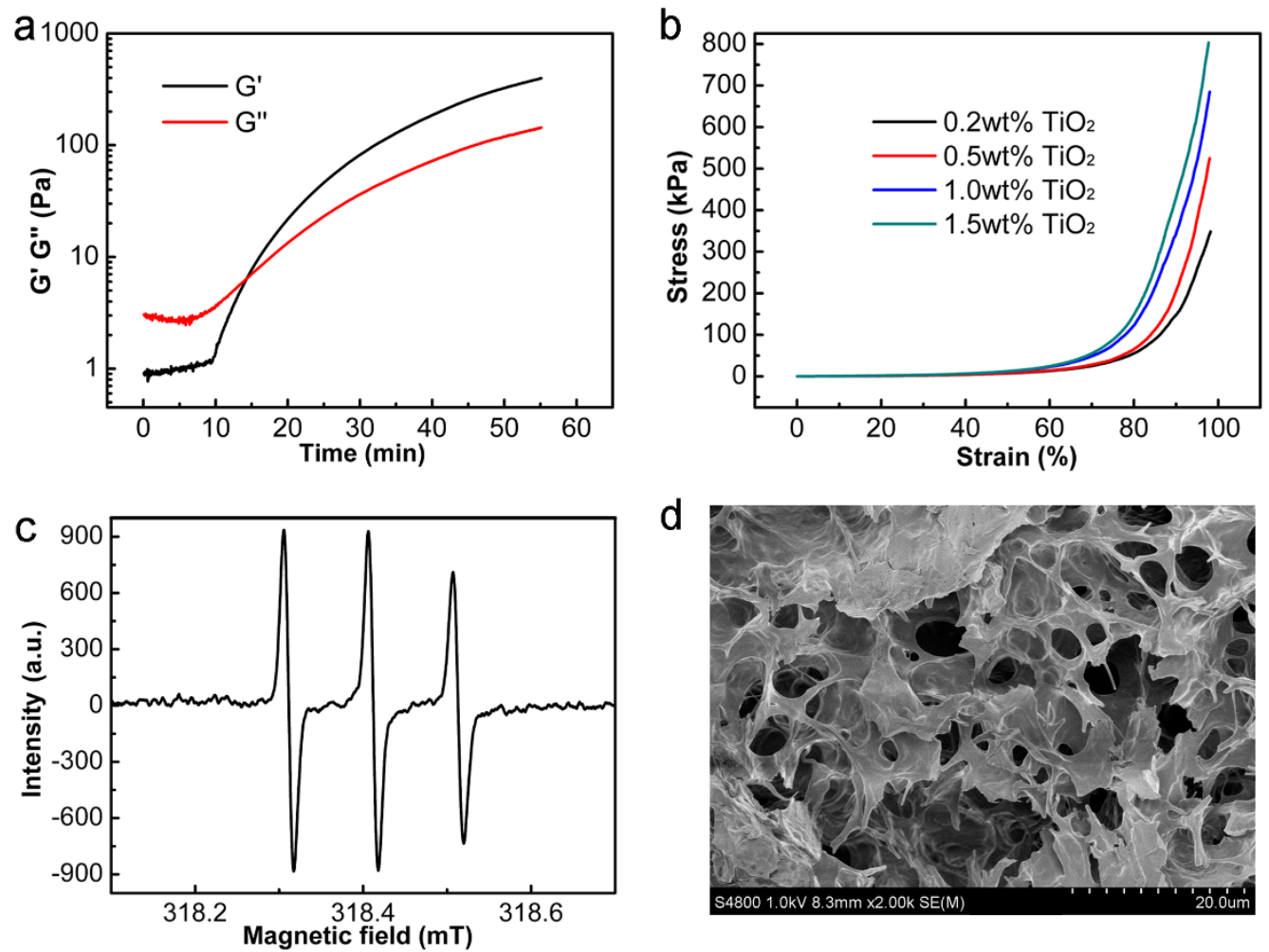

Figure $2 \mid$ The gelation mechanism, mechanical strength, and porous structure of ionogels. (a) Dynamic time sweep of a gelation system containing 89 wt $\% \mathrm{BMIMBF}_{4}, 1 \mathrm{wt} \% \mathrm{TiO}_{2}-\mathrm{NPs}$, and $10 \mathrm{wt} \% \mathrm{HEMA}$ at a strain of $1 \%$ and a frequency of $1 \mathrm{rad} \mathrm{s}^{-1}$. (b) Compressive properties of the $\mathrm{BMIMBF}_{4}$-based ionogels with different $\mathrm{TiO}_{2}$ concentrations. (c) EPR spectra of $\mathrm{BMIMBF}_{4}$ consisting of $\mathrm{TiO}_{2}$ and $\mathrm{HEMA}$ under UV irradiation for 15 minutes.

(d) SEM images of a freeze-dried $\mathrm{BMIMBF}_{4}$-based gel after replacing the ionic liquid with water.

our actuator consist of two layers of activated carbon and two layers of gold foil. Activated carbon is chosen for the electrodes, because it can generate a high specific area and acts as the ion storage carrier. Gold foil is a conventional and useful electrode material for fabricating the actuator due to its flexibility, conductivity and low activity in electrochemical reactions. The displacement of the assembled actuator was measured by periodically changing the voltage applied on an actuator strip that is clamped between two titanium contacts. Figures $3 \mathrm{~b}$ and $3 \mathrm{c}$ show the visible movement of the ionogel-based electrochemical actuators with and without loading. Therefore, a series of actuators with different parameters were processed, fabricated, and characterised. A camera is used to monitor the accurate displacement continuously. Figures $3 \mathrm{~d}$ and $3 \mathrm{e}$ show a typical time composition of current and displacement response of the ionogel-based actuator to the applied driving voltage of $\pm 3.5 \mathrm{~V}$. The charging current is observed to decay over time when the voltage is applied to the actuator.

\section{Discussion}

The actuating behaviour of the gel-electrolyte-based actuator is based on an ion transfer mechanism. The recorded electric current in the figure demonstrates that the actuator exhibits a capacitive mechanism of the electric double layer formed at the interface of the activated carbon in the electric double-layer device. As shown in Figures $4 \mathrm{a}$ and $4 \mathrm{~b}$, the formation of the electric double layer causes the swelling of the cathodic side and the deswelling of the anodic side, which is responsible for the direction of the movement. The mechanism of our actuator can be explained as an electric-double-layer capacitor. When a voltage is applied between two electrodes, the cations $\left(\mathrm{BMIM}^{+}\right)$and anions $\left(\mathrm{BF}_{4}{ }^{-}\right)$in the ionogel-electrolyte are transferred to the cathode- and anode-activated carbon layers, respectively. The ion transportation is most likely to result in the swelling of the cathode layer and the shrinkage of the anode layer due to the larger size of $\mathrm{BMIM}^{+}$than $\mathrm{BF}_{4}^{-}$. As a result, the bending displacement is always directed toward the anodic side. Cyclic voltammograms, which can characterize the charge-discharge process, were carried out to estimate the capacitance. Figure S4 shows the cyclic voltammograms of the actuators, and the calculated capacitance was $102 \mathrm{~F} / \mathrm{g}$ (at $5 \mathrm{mV} / \mathrm{s}$ ). Based on the volume change of the transferring ions ${ }^{53}$, we can ideally represent the displacement measurements (Figure 5) and calculate the rotating angle and displacement:

$$
D=\operatorname{Ltan} \frac{2 k L U}{W^{2}}
$$

(Equation S1)

where, $D$ is the displacement, $L$ is the free length of the actuator, $U$ is the applied voltage, $W$ is the thickness of the actuator. And $k$ is a hybrid constant, which was a function of the specific capacitance of the actuator, the density and thickness of the activated carbon film, and the volume of the cation and the anion.

To confirm the hypothesis, the relationship between the generated displacement with length, thickness, voltage, and frequency were measured and are listed in Figure 6. There is a positive correlation between the displacement and the length of the actuator. As the length increases from $1 \mathrm{~cm}$ to $3 \mathrm{~cm}$, the displacement shows an increase from $0.6 \mathrm{~mm}$ to $3.3 \mathrm{~mm}$. The displacement is inversely proportional to the thickness of the actuator. However, the smaller displacement with a thickness of $0.2 \mathrm{~mm}$ can be attributed to the limited amount of charged ions that can access the electrode-electrolyte interface. This is because the surface area of the electrodes plays an important role in achieving high-performance flexible supercapacitor ${ }^{54}$. Similarly, the increase in applied voltage tends to increase the displacement response of the actuator. When the applied voltage increased from $1 \mathrm{~V}$ to $4 \mathrm{~V}$, an increase in the displacement response was observed from $0.1 \mathrm{~mm}$ to $5.9 \mathrm{~mm}$. Figure $6 \mathrm{~d}$ depicts the frequency dependence of the generated strain for the actuators. When the generated strain decreased from $1.28 \%$ to $0.007 \%$, we 
a

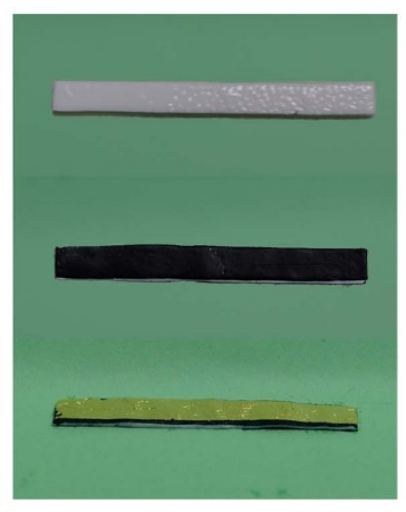

b
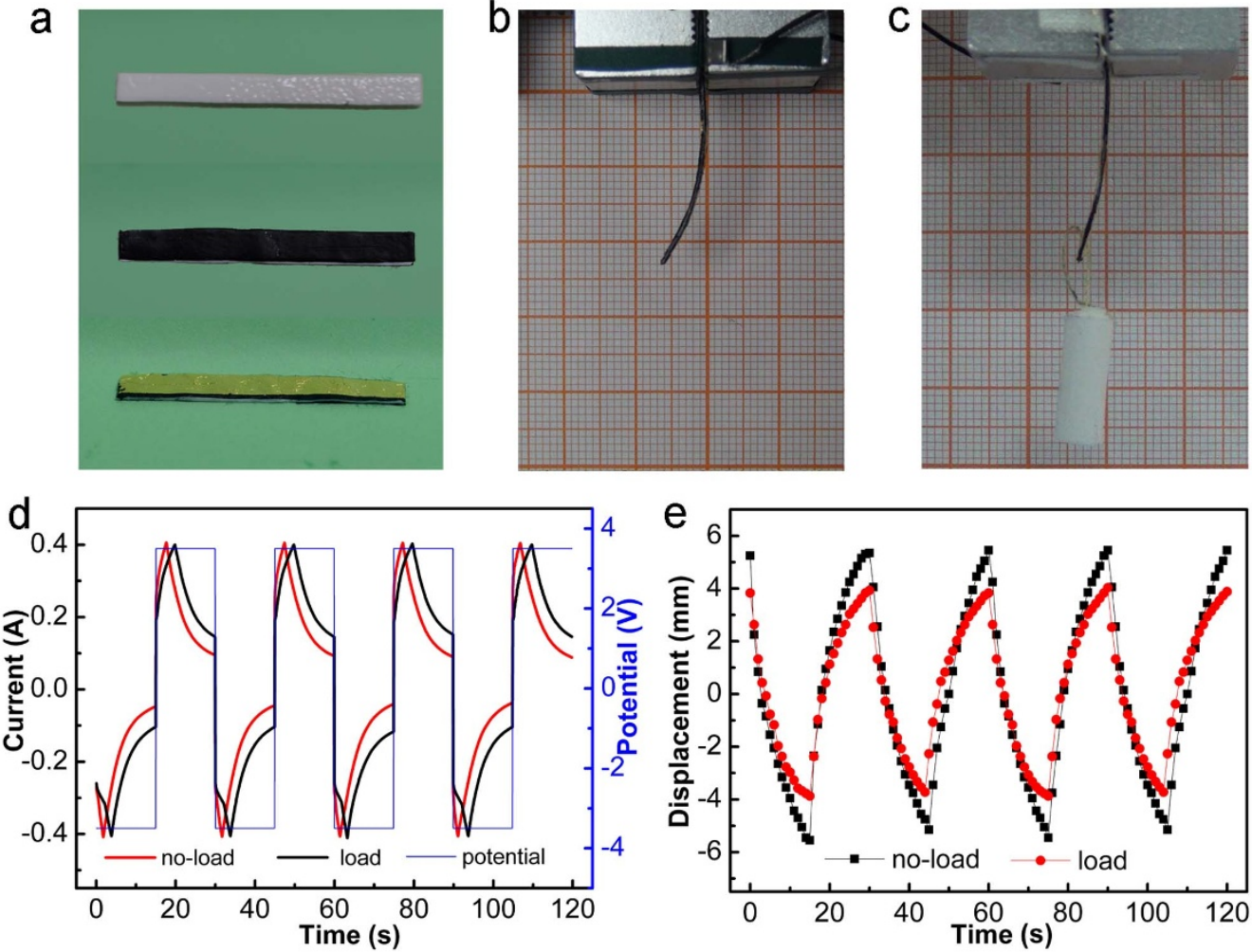

Figure 3 Actuating properties of the ionogel-based actuators. (a) Photograph of the fabrication process of the ionogel-based actuator. (b) Strain of the actuator under an applied voltage of $\pm 3.5 \mathrm{~V}$. (c) The loading ability of the ionogel-based actuator under an applied voltage of $\pm 3.5 \mathrm{~V}$. (d) Current characteristics of the actuators under loading and unloading conditions when a rectangular square-wave voltage of $\pm 3.5 \mathrm{~V}$ was applied. (e) Bending displacement of the actuator under a square-wave voltage of $\pm 3.5 \mathrm{~V}$ under loading and unloading conditions, respectively.

observed an extremely large frequency response ranging from $0.005 \mathrm{~Hz}$ to $17 \mathrm{~Hz}$. As illustrated in the literature ${ }^{55}$, the actuator can be equivalent to a simple resistor-capacitor (RC) circuit and the quantity of electricity (Q) can be illustrated as followed:

$$
Q=\frac{U C}{2 \pi f R C+1}
$$

(Equation S2)

where, $U$ is the voltage value, $C$ is the capacitance, $R$ is the resistor, and $f$ is the frequency of alternating voltage (sinusoidal wave for example). Therefore, the decrease in the generated strain is attributed to the decrease in the quantity of electricity accompanied with the increase in frequency.

With the same additional mass loading to the original weight $(70 \mathrm{mg})$, the actuator still shows a large displacement response. The accumulated charge $(\mathrm{Q})$ of each half period can be calculated by integrating the current. The accumulated charges are calculated to be $1.8 \mathrm{C}$ and $2.1 \mathrm{C}$, respectively. The displacement response of the actuator decreases from $5.6 \mathrm{~mm}$ to $3.9 \mathrm{~mm}$, when the actuator changes from the unloading state to the loading state. The actuator under loading condition performs an increased amount of the charged ions along with a slight decrease in displacement. The addition of mass loading to the flexible gel actuator results in an increase in the length and conductive pathways, which increases the amount of charged ions that can access the electrode-electrolyte interface. The surface areas of the electrodes are also occupied efficiently to increase the accumulated charges. The ionogel can be moulded as a cantilevered bender; the decreased displacement can be attributed to the gravity of the load. The bending moment $\left(M_{d}\right)$ can be expressed as:

$$
M_{d}=\mathrm{M}-M_{G}
$$

(Equation S3)

where, $M$ is the driven movement and $M_{G}$ is the moment caused by the gravity of load. Hence, we can conclude that if the ionogel moves with the load, the bending moment will decrease, reducing the bending moment in the $y$ axis. Compared to a traditional actuator, our actuator possesses good loading ability with up to 1.5 times the original weight (Figure S5). Based on the loading ability, the ionogel electrolyte-based actuator can be used as a robot manipulator. As shown in Figures $4 \mathrm{c}-\mathrm{f}$, our actuator can be designed as an artificial robot to accomplish a catch-and-place cycle with a light object by adjusting the voltage. Therefore, our actuator can realise the goal of grabbing objects. In view of the excellent thermostability and low melting point of ionic liquids ${ }^{56,57}$, we measured the behaviour of the actuators in harsh temperature environments. It is interesting that the ionogel-based actuators can still display a large displacement not only in a high temperature of $100^{\circ} \mathrm{C}$ (Figure S6) but also in a low temperature of $-10^{\circ} \mathrm{C}$ (Figure S7).

In summary, we report a novel electro-active actuator based on supramolecular nanocomposite ionogels. The ionogels are produced by a $\mathrm{TiO}_{2}$-NPs-initiated UV polymerization, and can be used as electrolytes in an actuator due to their high strength and easy ionic diffusion channels. The electro-active actuator exhibits a maximum of $5.9 \mathrm{~mm}$ bending displacement and a maximum of 1.5 times the loading ability under a voltage of $3.5 \mathrm{~V}$. Interestingly, our actuator can be designed as an artificial robot to catch and place objects by tuning the voltage. Our ionogel-based actuator solves the common problems (i.e., displacement and loading) faced by the actuators fabricated by the complicated methods. Furthermore, our ionogelbased actuators can be applied in harsh temperature environments.

\section{Methods}

EPR Analysis. The UV light induced free radical polymerization is monitored by EPR Spectrometer (A300, Bruker). In a typical process, the precursor mixture $\left(\mathrm{BMIMBF}_{4}\right.$, $\mathrm{TiO}_{2}$, and HEMA) was placed in the spectrometer and irradiated in situ by ultraviolet light (average intensity of $20.0 \mathrm{mw} / \mathrm{cm}^{2}$, at $365 \mathrm{~nm}$ ). The spectrum was recorded after 15 minutes of reaction. 
Activated Carbon

Ionic Liquid

$\operatorname{PHEMA}\left(\mathrm{TiO}_{2}\right)$

a

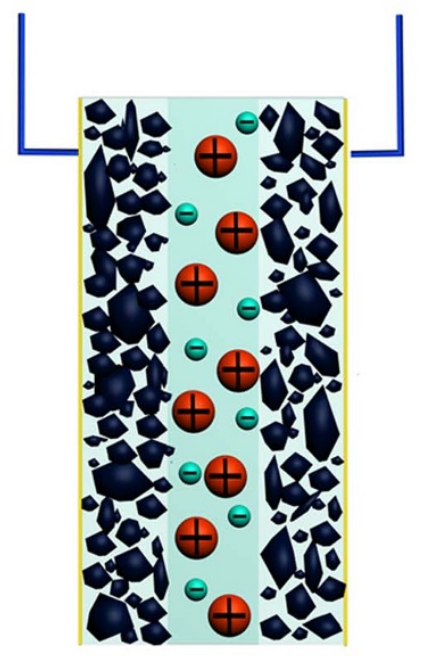

b

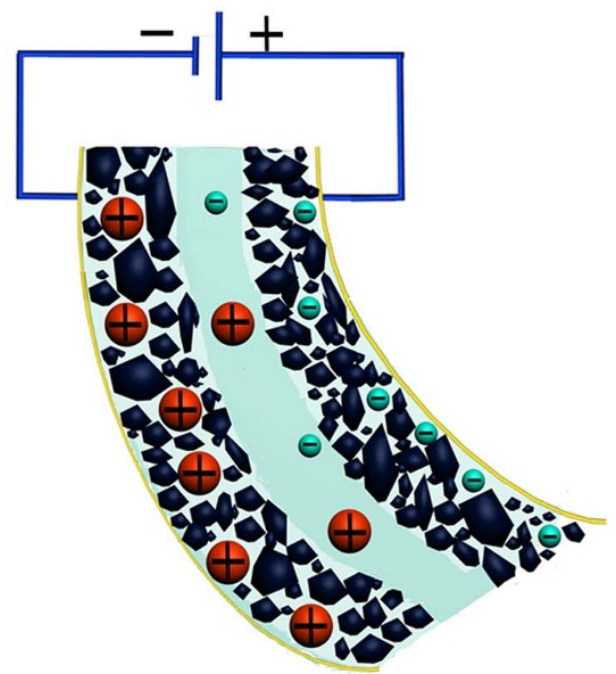

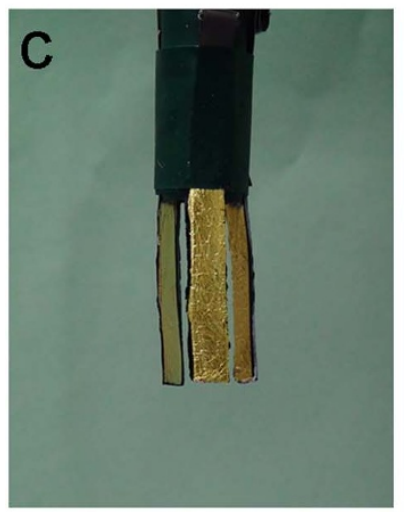
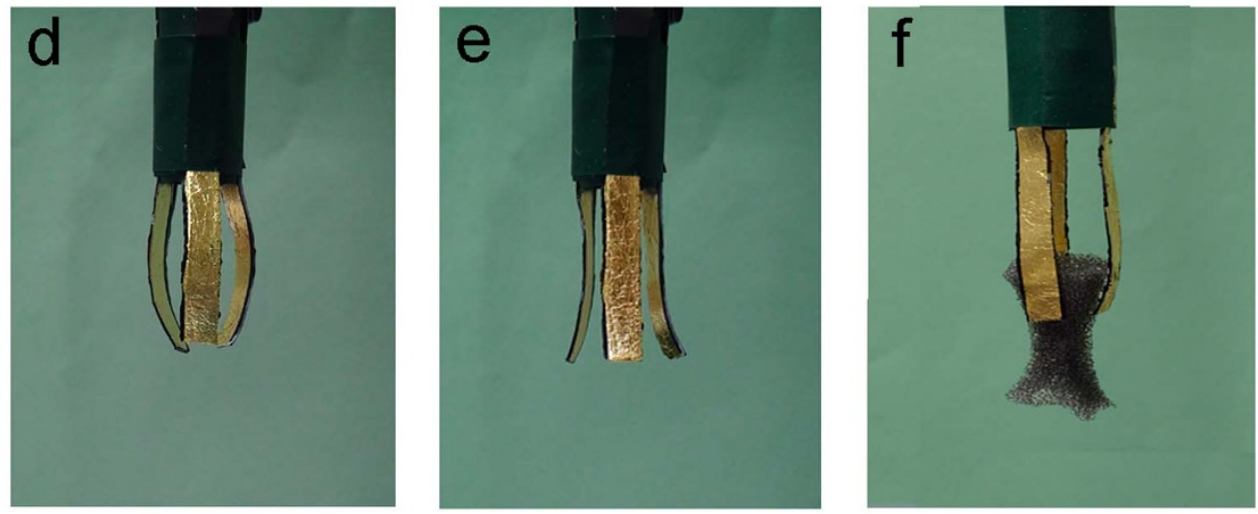

Figure 4 Schematic diagram of BMIMBF$_{4}$-gel-electrolyte-based actuator based on an ion transfer mechanism. (a) The electric-double-layer formed inside the porous media of activated carbon. (b) Strain of the actuator under an applied voltage. (c) The model of the robot manipulator; (d) under an applied voltage; (e) under an inversely applied voltage. (f) Photograph of the robot manipulator grabbing an object (180 mg).

Pre-treatment of SEM samples. The ionogel sample for SEM analysis was firstly put into distilled water for long maceration period of ten days (the distilled water was changed three times a day). After that, the obtained hydrogel was cut into a small cube

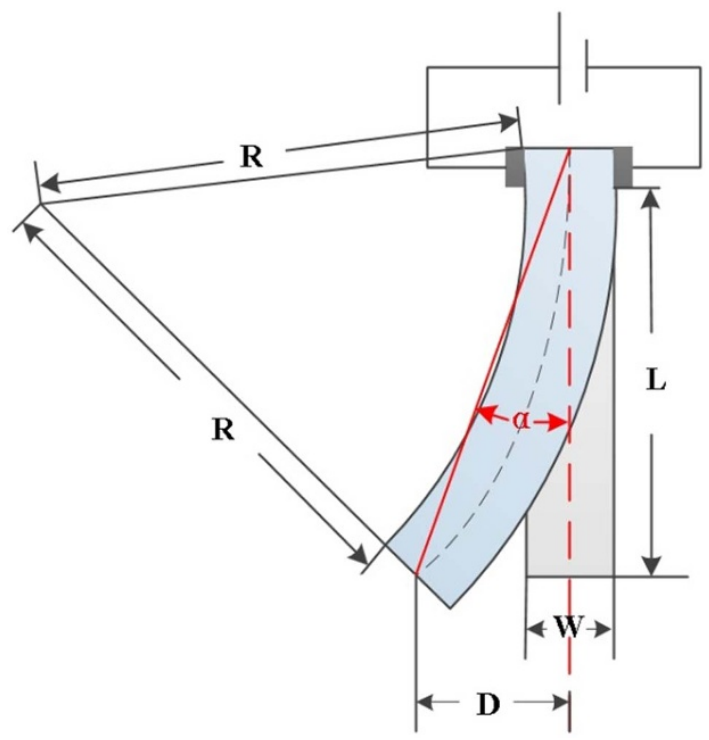

Figure 5 | Schematic representation for displacement measurements.
$(5 \times 10 \times 5 \mathrm{~mm})$. Then, the sample was freeze-dried (Freezing Dryer, Scientz-10N, Ningbo Scientz Biotechnology Co., Ltd.) and sputter-coated with gold for observation by scanning electron microscope (Hitachi S-4800, JEOL, Tokyo, Japan) at an accelerating voltage of $1 \mathrm{kV}$.

Mechanical Measurement. The compressive stress-strain tests were performed on ionogels via a tensile-compressive tester (FR-108B, Farui Co.). The cylindrical ionogel (13 $\mathrm{mm}$ in diameter and $6 \mathrm{~mm}$ in thickness) was compressed at a rate of $1 \mathrm{~mm}$ $\min ^{-1}$. The tensile property of the ionogel was also measured. The tested part of the specimen is $5 \mathrm{~mm}$ in width and $10 \mathrm{~mm}$ in length with a thickness of $1 \mathrm{~mm}$. The tensile test of the $\mathrm{BMIMBF}_{4}$-based ionogel was conducted at a rate of $10 \mathrm{~mm} / \mathrm{min}$. The average data of three parallel tests were reported.

Rheological Analysis. The rheological property was carried out with a Rheostress RS6000 rheometer (Haake Instrument, Germany) to understand the gelation kinetics of the ionic liquid-based system containing $89 \mathrm{wt} \% \mathrm{BMIMBF}_{4}, 1 \mathrm{wt} \% \mathrm{TiO}_{2}-\mathrm{NPs}$, and $10 \mathrm{wt} \%$ HEMA. Dynamic time sweep was carried out at a strain of $1 \%$ and a frequency of $1 \mathrm{rad} \mathrm{s}^{-1}$ to monitor the storage modulus $\left(\mathrm{G}^{\prime}\right)$ and loss modulus $\left(\mathrm{G}^{\prime \prime}\right)$.

TGA Measurement. The thermal stability of ionogels was characterized by TGA. $5 \mathrm{mg}$ of the gel sample was placed in a sealed aluminum oxide pans. The samples with different time of UV-radiation were heated from room temperature to $600^{\circ} \mathrm{C}$ at a heating rate of $15^{\circ} \mathrm{C} / \mathrm{min}$ under nitrogen atmosphere. Because the ionic liquid has essentially zero vapor pressure, the mass loss of volatiles resulting from the unreacted monomers in the ionogels can be detected by TGA to monitor the conversion of polymerization.

Electrochemical Analysis. The porous electrodes for the actuator were prepared from a mixture of activated charcoal powder, $60 \mathrm{wt} \%$ polytetrafluoroethylene binder, and acetylene black conductor (with a w/w ratio of $80: 10: 10$ ) by spreading the slurry 

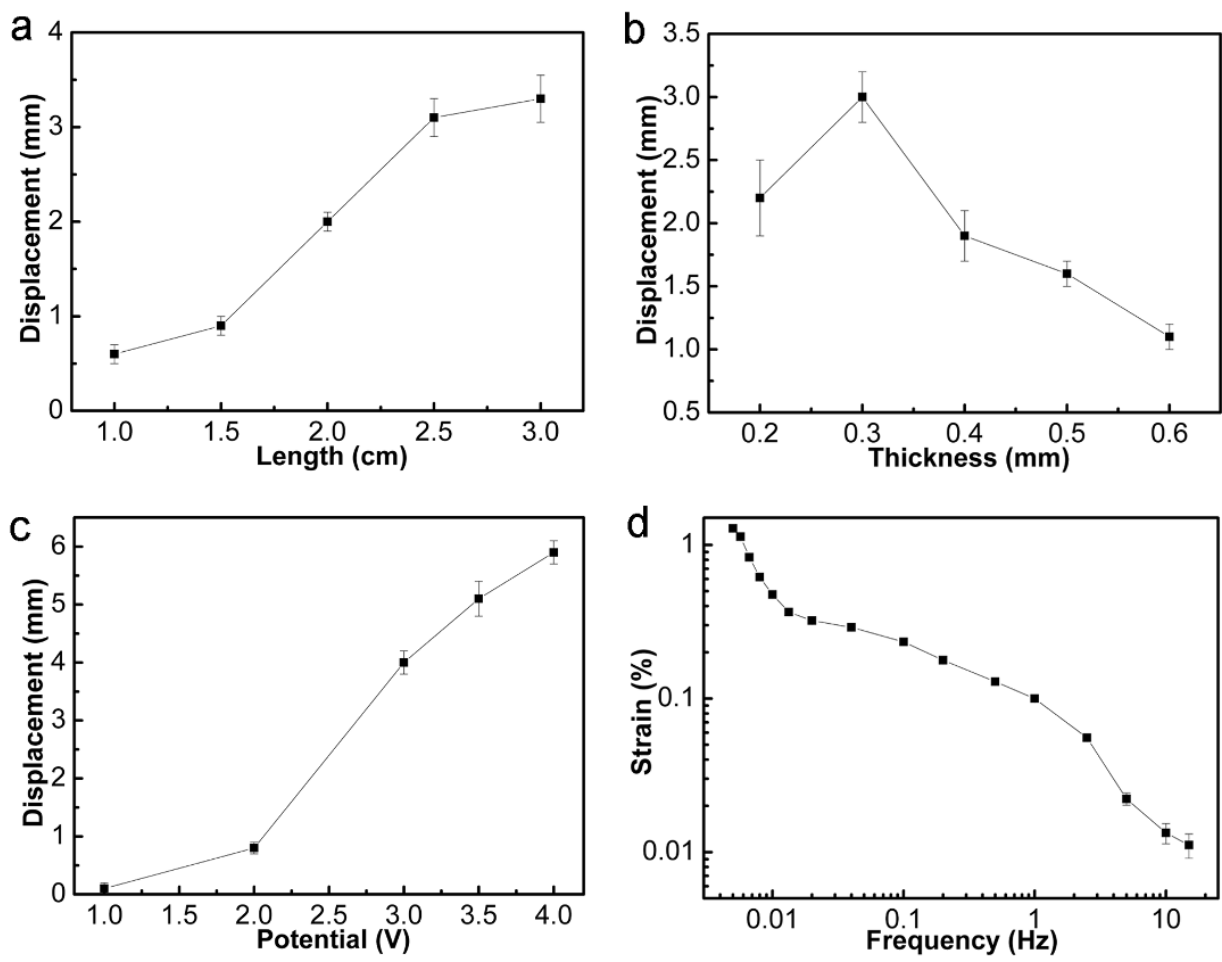

Figure 6 The relationship between the generated displacements and various parameters of ionogel-based actuators (width: 5 mm). (a). The influence of length at fixed voltage $(2.5 \mathrm{~V})$ and thickness $(0.3 \mathrm{~mm})$. (b) The influence of thickness at fixed voltage $(2.5 \mathrm{~V})$ and length $(2.5 \mathrm{~cm})$. (c) Voltagedependent displacements at fixed thickness $(0.3 \mathrm{~mm})$ and length $(2.5 \mathrm{~cm})$. (d) Frequency-dependent strain generated $(\varepsilon)$ at fixed thickness $(0.3 \mathrm{~mm})$, length $(3 \mathrm{~cm})$, and a standard sinusoidal waveform (the peak voltage is $4.7 \mathrm{~V}$ ).

on a titanium plate. The activated charcoal electrodes with mass loadings of about $3 \mathrm{mg} / \mathrm{cm}^{2}$ were dried in vacuum at $120^{\circ} \mathrm{C}$ for $24 \mathrm{~h}$. As for the fabrication of the ionogel-based actuators, the middle layer is the ionogel which contains ionic liquid as the electrolyte. The outer layers include two layer of activated carbon and two layers of gold foil. Considering the fragility of gold foil, a piece of titanium was covered on the surface of gold foil as electrode. To demonstrate the applicability of ionogels as smart actuators, a novel bending actuator is processed, fabricated, and tested. After comprehensive consideration, a $25 \mathrm{~mm} \times 5 \mathrm{~mm}$ actuator was chosen as the optimal sample in the tests of loading ability. The cyclic voltammetry measurement of ionogel-based actuator was conducted at different sweep rate $(5 \mathrm{mV} / \mathrm{s}, 10 \mathrm{mV} / \mathrm{s}$, $50 \mathrm{mV} / \mathrm{s}$, and $100 \mathrm{mV} / \mathrm{s})$ using a $\mathrm{CHI} 660 \mathrm{D}$ electrochemical work station $(\mathrm{CH}$ Instruments). The driving performance measurements at both high temperature $\left(100^{\circ} \mathrm{C}\right)$ and low temperature $\left(-10^{\circ} \mathrm{C}\right)$ were carried out with a period of $30 \mathrm{~s}$ under the applied voltage of $\pm 3.5 \mathrm{~V}$.

1. Madden, J. D. Mobile robots: motor challenges and materials solutions. Science 318, 1094-1097 (2007).

2. Pelrine, R., Kornbluh, R., Pei, Q. \& Joseph, J. High-speed electrically actuated elastomers with strain greater than 100\%. Science 287, 836-839 (2000).

3. Hammock, M. L. et al. 25th Anniversary Article: The Evolution of Electronic Skin (E-Skin): A Brief History, Design Considerations, and Recent Progress. Adv. Mater. 25, 5997-6038 (2013).

4. Feinberg, A. W. et al. Muscular thin films for building actuators and powering devices. Science 317, 1366-1370 (2007)

5. Sitti, M. Miniature devices: Voyage of the microrobots. Nature 458, 1121-1122 (2009).

6. Wu, Y., Alici, G., Madden, J. D., Spinks, G. M. \& Wallace, G. G. Soft mechanical sensors through reverse actuation in polypyrrole. Adv. Funct. Mater. 17, 3216-3222 (2007)

7. Liu, S. et al. High Electromechanical Response of Ionic Polymer Actuators with Controlled-Morphology Aligned Carbon Nanotube/Nafion Nanocomposite Electrodes. Adv. Funct. Mater. 20, 3266-3271 (2010).

8. Terasawa, N. \& Takeuchi, I. Electrochemical property and actuation mechanism of an actuator using three different electrode and same electrolyte in air: Carbon nanotube/ionic liquid/polymer gel electrode, carbon nanotube/ionic liquid gel electrode and Au paste as an electrode. Sens. Actuators, B 145, 775-780 (2010).

9. Liang, J. et al. Electromechanical actuators based on graphene and graphene/ Fe3O4 hybrid paper. Adv. Funct. Mater. 21, 3778-3784 (2011).

10. Liu, Y. et al. Direct Observation of Ion Distributions near Electrodes in Ionic Polymer Actuators Containing Ionic Liquids. Sci. Rep. 3, 973 (2013).

11. Kong, L. \& Chen, W. Carbon Nanotube and Graphene-based Bioinspired Electrochemical Actuators. Adv. Mater. 26, 1025-1043 (2014).
12. Park, S., An, J., Suk, J. W. \& Ruoff, R. S. Graphene-Based Actuators. Small 6 , 210-212 (2010)

13. Shin, K.-Y., Hong, J.-Y. \& Jang, J. Flexible and transparent graphene films as acoustic actuator electrodes using inkjet printing. Chem. Commun. 47, 8527-8529 (2011).

14. Palmre, V. et al. Electroactive polymer actuators with carbon aerogel electrodes. J. Mater. Chem. 21, 2577-2583 (2011).

15. Li, J. et al. Superfast-response and ultrahigh-power-density electromechanical actuators based on hierarchal carbon nanotube electrodes and chitosan. Nano lett. 11, 4636-4641 (2011).

16. Carpi, F., Bauer, S. \& De Rossi, D. Stretching dielectric elastomer performance. Science 330, 1759-1761 (2010).

17. Opris, D. M. et al. New silicone composites for dielectric elastomer actuator applications in competition with acrylic foil. Adv. Funct. Mater. 21, 3531-3539 (2011).

18. Pelrine, R., Kornbluh, R. \& Kofod, G. High-Strain Actuator Materials Based on Dielectric Elastomers. Adv. Mater. 12, 1223-1225 (2000).

19. Akbari, S. \& Shea, H. R. An array of $100 \mu \mathrm{m} \times 100 \mu \mathrm{m}$ dielectric elastomer actuators with $80 \%$ strain for tissue engineering applications. Sens. Actuators, A 186, 236-241 (2012).

20. He, X., Li, C., Chen, F. \& Shi, G. Polypyrrole microtubule actuators for seizing and transferring microparticles. Adv. Funct. Mater. 17, 2911-2917 (2007).

21. Fukuda, K. et al. A 4 V Operation, Flexible Braille Display Using Organic Transistors, Carbon Nanotube Actuators, and Organic Static Random-Access Memory. Adv. Funct. Mater. 21, 4019-4027 (2011).

22. Shahinpoor, M., Bar-Cohen, Y., Simpson, J. \& Smith, J. Ionic polymer-metal composites (IPMCs) as biomimetic sensors, actuators and artificial muscles-a review. Smart Mater. Struct. 7, R15 (1998).

23. Jo, C., Pugal, D., Oh, I.-K., Kim, K. J. \& Asaka, K. Recent advances in ionic polymer-metal composite actuators and their modeling and applications. Prog. Polym. Sci. 38, 1037-1066 (2013).

24. Kim, K. J. \& Shahinpoor, M. A novel method of manufacturing three-dimensional ionic polymer-metal composites (IPMCs) biomimetic sensors, actuators and artificial muscles. Polymer 43, 797-802 (2002).

25. Shahinpoor, M. \& Kim, K. J. Ionic polymer-metal composites: I. Fundamentals. Smart Mater. Struct. 10, 819 (2001).

26. Le Bideau, J., Viau, L. \& Vioux, A. Ionogels, ionic liquid based hybrid materials. Chem. Soc. Rev. 40, 907-925 (2011).

27. Buchtová, N., Guyomard-Lack, A. \& Le Bideau, J. Biopolymer based nanocomposite ionogels: high performance, sustainable and solid electrolytes. Green Chem. 16, 1149-1152 (2014). 
28. Néouze, M.-A., Bideau, J. L., Gaveau, P., Bellayer, S. \& Vioux, A. Ionogels, new materials arising from the confinement of ionic liquids within silica-derived networks. Chem. Mater. 18, 3931-3936 (2006).

29. Armand, M. et al. Ionic-liquid materials for the electrochemical challenges of the future. Nat. Mater. 8, 621-629 (2009).

30. Lu, L. et al. Graphene-Stabilized Silver Nanoparticle Electrochemical Electrode for Actuator Design. Adv. Mater. 25, 1270-1274 (2013).

31. Lu, L. \& Chen, W. Biocompatible composite actuator: a supramolecular structure consisting of the biopolymer chitosan, carbon nanotubes, and an ionic liquid. $A d v$. Mater. 22, 3745-3748 (2010).

32. Lu, L. et al. Highly stable air working bimorph actuator based on a graphene nanosheet/carbon nanotube hybrid electrode. Adv. Mater. 24, 4317-4321 (2012).

33. Fukushima, T., Asaka, K., Kosaka, A. \& Aida, T. Fully Plastic Actuator through Layer-by-Layer Casting with Ionic-Liquid-Based Bucky Gel. Angew. Chem. Int. Ed. 44, 2410-2413 (2005).

34. Mukai, K. et al. Highly Conductive Sheets from Millimeter-Long Single-Walled Carbon Nanotubes and Ionic Liquids: Application to Fast-Moving, Low-Voltage Electromechanical Actuators Operable in Air. Adv. Mater. 21, 1582-1585 (2009).

35. Takeuchi, I. et al. Electromechanical behavior of fully plastic actuators based on bucky gel containing various internal ionic liquids. Electrochim. Acta 54, 1762-1768 (2009)

36. Lee, J. \& Aida, T. "Bucky gels" for tailoring electroactive materials and devices: the composites of carbon materials with ionic liquids. Chem. Commun. 47 6757-6762 (2011).

37. Calvert, P. Hydrogels for soft machines. Adv. Mater. 21, 743-756 (2009).

38. Gayet, F. et al. Polymer nanocomposite ionogels, high-performance electrolyte membranes. J. Mater. Chem. 20, 9456-9462 (2010).

39. Liu, X., Wu, D., Wang, H. \& Wang, Q. Self-Recovering Tough Gel Electrolyte with Adjustable Supercapacitor Performance. Adv. Mater. 26, 4370-4375 (2014).

40. Fox, J. et al. High-strength, healable, supramolecular polymer nanocomposites J. Am. Chem. Soc. 134, 5362-5368 (2012).

41. Gayet, F. et al. Unique combination of mechanical strength, thermal stability, and high ion conduction in PMMA - Silica nanocomposites containing high loadings of ionic liquid. Chem. Mater. 21, 5575-5577 (2009).

42. Liu, X. et al. Tough BMIMCl-based Ionogel Exhibits Excellent and Adjustable Performance in High-temperature Supercapacitor. J. Mater. Chem. A 2, 11569-11573 (2014)

43. Seki, S. et al. Distinct difference in ionic transport behavior in polymer electrolytes depending on the matrix polymers and incorporated salts. J. Phys. Chem. B 109, 3886-3892 (2005).

44. Zhang, M. et al. Self-Healing Supramolecular Gels Formed by Crown Ether Based Host-Guest Interactions. Angew. Chem. Int. Ed. 51, 7011-7015 (2012).

45. Yan, X. et al. A Multiresponsive, Shape-Persistent, and Elastic Supramolecular Polymer Network Gel Constructed by Orthogonal Self-Assembly. Adv. Mater. 24, 362-369 (2012).

46. Wang, Q. et al. High-water-content mouldable hydrogels by mixing clay and a dendritic molecular binder. Nature 463, 339-343 (2010).

47. Zhang, D. et al. Semiconductor nanoparticle-based hydrogels prepared via selfinitiated polymerization under sunlight, even visible light. Sci. Rep. 3, 1399 (2013).

48. Dong, S. et al. A Dual-Responsive Supramolecular Polymer Gel Formed by Crown Ether Based Molecular Recognition. Angew. Chem. Int. Ed. 50, 1905-1909 (2011).
49. Dong, S. et al. A crown ether appended super gelator with multiple stimulus responsiveness. Adv. Mater. 24, 3191-3195 (2012).

50. Yu, G., Yan, X., Han, C. \& Huang, F. Characterization of supramolecular gels. Chem. Soc. Rev. 42, 6697-6722 (2013).

51. Strehmel, V. et al. [Free radical polymerization of methacrylates in ionic liquids] Ionic liquids in polymer systems: solvents, additives, and novel applications. [Brazel, C. S., Rogers, R. D. (eds.)] [17-23], (Amer Chemical Society, Washington, DC, 2005).

52. Maziz, A. et al. Demonstrating kHz Frequency Actuation for Conducting Polymer Microactuators. Adv. Funct. Mater. DOI: 10.1002/adfm.201400373 (2014).

53. Sugino, T., Kiyohara, K., Takeuchi, I., Mukai, K. \& Asaka, K. Actuator properties of the complexes composed by carbon nanotube and ionic liquid: the effects of additives. Sens. Actuators, B 141, 179-186 (2009).

54. Frackowiak, E. \& Beguin, F. Electrochemical storage of energy in carbon nanotubes and nanostructured carbons. Carbon 40, 1775-1787 (2002).

55. Saito, S. et al. Development of a soft actuator using a photocurable ionic gel. J. Micromech. Microeng. 19, 035005 (2009).

56. Rogers, R. D. \& Seddon, K. R. Ionic liquids--solvents of the future? Science $\mathbf{3 0 2}$ 792-793 (2003).

57. Hapiot, P. \& Lagrost, C. Electrochemical reactivity in room-temperature ionic liquids. Chem. Rev. 108, 2238-2264 (2008).

\section{Acknowledgments}

This work was supported by the National Natural Science Foundation of China (No. 21274111, 51275360), the Program for New Century Excellent Talents in University of Ministry of Education of China (NECT-11-0386), the Fundamental Research Funds for Central Universities, and the Recruitment Program of Global Experts.

\section{Author contributions}

X.L. synthesised the ionogels and analysed their properties; Z.W., H.T. and T.S. assisted with electrochemical analysis; X.L., B.H. and Q.W. designed experiments and analysed data; B.H. and Q.W. proposed the research and wrote the paper.

\section{Additional information}

Supplementary information accompanies this paper at http://www.nature.com/ scientificreports

Competing financial interests: The authors declare no competing financial interests. How to cite this article: Liu, X. et al. Tough Nanocomposite Ionogel-based Actuato Exhibits Robust Performance. Sci. Rep. 4, 6673; DOI:10.1038/srep06673 (2014).

This work is licensed under a Creative Commons Attribution-NonCommercialNoDerivs 4.0 International License. The images or other third party material in this article are included in the article's Creative Commons license, unless indicated otherwise in the credit line; if the material is not included under the Creative Commons license, users will need to obtain permission from the license holder in order to reproduce the material. To view a copy of this license, visit http:// creativecommons.org/licenses/by-nc-nd/4.0/ 